\title{
Revisiting Two Robust Techniques for Contaminant Removal from Road Runoff
}

\author{
Péter Budai ${ }^{1 *}$ \\ 1 Department of Sanitary and Environmental Engineering, \\ Faculty of Civil Engineering, \\ Budapest University of Technology and Economics, \\ H-1111 Budapest, Műegyetem rakpart 3., K. ép. mf. 33., Hungary \\ *Corresponding author, e-mail: budai.peter@epito.bme.hu
}

Received: 08 February 2019, Accepted: 14 March 201X, Published online: 15 April 2019

\begin{abstract}
Treatment of road runoff is a requisite for any environmentally sound infrastructure design. However, investment and maintenance budget is often a limiting factor during the planning and the operation phase of such projects. In order to cost-efficiently decrease the loads of a wide range of contaminants that are usually present in road runoff (posing a long-term threat to the aquatic and soil environments), simple and robust techniques are sought for. The paper deals with the re-evaluation of two such processes, sedimentation and filtration, putting emphasis on using authentic runoff samples during the tests in order to properly characterize the performance of these easy-to-manage solutions in this specific field of application. The results presented in this paper are aimed to aid the proper design of low-cost, low-maintenance road runoff treatment facilities, serving with background information that can be used to ensure that the expectations for the degree of pollutant removal are surely met.
\end{abstract}

Keywords

road runoff, pollution, treatment, contaminant removal

\section{Introduction}

Rainfall runoff originating from paved surfaces, most importantly roads, is characterized by the occurrence of a range of organic and inorganic pollutant materials [1-6]. Typical contaminants of environmental concern are mineral oil derived hydrocarbons and various species of heavy metals. The sources of these materials are either 1) fuel combustion, 2) leakage of liquids from vehicles, 3) abrasion processes (including brake, tire and road wear), 4) corrosion or 5) atmospheric deposition [7-11].

Non-gaseous traffic-borne pollutants accumulate by small increments on the impervious road surfaces during periods of dry weather $[12,13]$. These loads are later washed off by intermittent rainfall events [12, 14]. In the resulting runoff, contaminants are physically present in either solid or liquid (dissolved) forms. The most apparent constituents are suspended solid particles that travel with the flow and give a strong opaque grey color to the runoff. Liquid state pollutants are less visible (except when they are colored, such as floating oil patches), but nonetheless important components.
The consecutive runoff volumes deliver contamination towards the final recipients (often natural watercourses). During the transportation process, the partitioning of pollutants between solid and dissolved phase adapts to the changes in relevant water chemistry parameters (such as $\mathrm{pH}$ or redox potential in general) which affect the sensitive equilibrium between dissolution and precipitation, as well as adsorption and desorption. The hazards are different for dissolved and solid phase contaminants: the former are mobile and easily accessible for the aquatic ecosystem, while the latter (in particular, heavy metals) tend to be more persistent and pose long-term threat by accumulating in the bed material or in the soil (in case of infiltration).

The severity of the issue may seem minuscule on the event scale, but longer-term estimations justify the need for action in this field. For instance, the annual nationwide emission of $\mathrm{Cu}$ and $\mathrm{Zn}$ solely from vehicle tire and brake wear in Hungary was assessed as 80.7 and 96.3 metric tons, respectively, while their runoff loads were estimated to be 20.2 and 74.7 tons in 2008 [15]. 
Pollution mitigation strategies and practices include a range of solutions from source control to various endof-pipe treatment systems. The phasing out of lead from fuels and asbestos fibers from brake pads are good examples for the former strategy. Sadly, most other pollutants of road runoff cannot be fully eliminated in this manner, treatment systems are therefore essential to reduce impairment of the environment. Diverse forms of sedimentation basins and oil separator objects, vegetated swales, infiltration basins, various configurations of detention and retention ponds are employed alone or in combination to cope with the task. Oddly, in most cases, the design of such systems focuses solely on hydraulic loads; pollution reduction capabilities are rather just inferred. Although the performance of some projects are occasionally investigated by scientific studies, after years of operation, these are scarce and much often site-specific [16-21].

It is also a known fact that road infrastructure managers (municipal authorities, public road operators) are seeking solutions that are affordable and require little maintenance effort. Complex schemes, regardless of how effective may be, are generally not favored by the end users (which is reflected in the high number of neglected runoff treatment systems). The goal of this paper is to show that it is worth revisiting simple and inexpensive techniques and materials that are easy to implement and operate, by evaluating them using genuine runoff samples.

\section{Materials and methods}

In this study, two different experimental setups were investigated, each one being selective for distinct clusters of road runoff pollutants. Details of the experiments and the employed analytical procedures are presented in the following subsections.

\subsection{Sedimentation tests}

Settling is a simple physical separation technique based on gravitational forces, targeting the removal of solid state particles from liquid suspensions. The larger and heavier particles, the higher settling velocity results. Depending on the flow conditions and the time frame available for the process, various particle ranges will settle out from the suspension within a given volume. When perpendicular flow is present during the process, the sedimentation efficiency will decrease (therefore increasing the volume needed for a given result). Thoughtful flow routing (e. g. in a zigzag fashion) can provide effective attenuation of this effect.

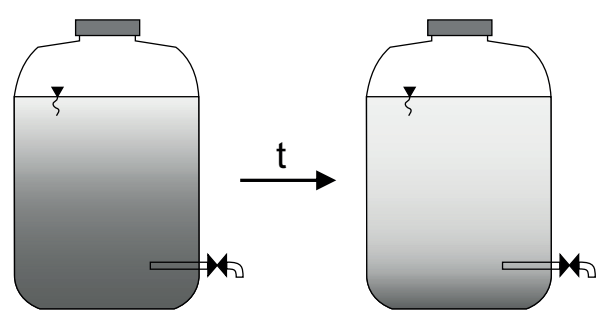

Fig. 1 Experimental setup used for the sedimentation tests

Road runoff is, by its own nature, not still. However, drainage infrastructure often involves sedimentation basins in order to separate suspended particulates from the flow. Such objects have a shape and volume that enables the flow to slow down, thus facilitating spontaneous settling. Rarely are these basins designed and sized with regard to the real-world runoff properties, though.

The aim of the experiment presented in this study was to measure and characterize the settling properties specific to suspended particles present in road runoff. Accordingly, actual runoff samples were used throughout the trials. Runoff was collected from heavily trafficked roads during various precipitation events, characterized by a wide range of rainfall intensity values $(1-47 \mathrm{~mm} / \mathrm{h}$ ), antecedent dry periods (up to 19 days) and concurrent traffic (500-3500 vehicles per hour). To enable the capture of the first flush (the initial phase of the runoff event, when contaminant concentrations are usually the highest), a passive sampler design was used, which is presented and discussed in detail in [22].

The experimental setup (Fig. 1) consisted of a $30 \mathrm{~L}$ plastic barrel equipped with a drain tap $5 \mathrm{~cm}$ above the bottom (allowing space for the accumulation of settled material). For each test, the barrel was filled up with raw runoff, homogenized by stirring and then left to settle for 8 hours. Samples were taken carefully (avoiding vertical mixing) using the tap. The first sample was drawn out 2 minutes after the start, followed by additional ones each 20 minutes until 1 hour, then each 40 minutes until 3 hours, and finally at 4, 6 and 8 hours. Six independent tests were executed, resulting 60 samples altogether. Along with total suspended solids (TSS), measured from all of the collected samples, total petroleum hydrocarbons (TPH) were also determined for one of the tests.

\subsection{Filtering tests}

Filtering is another popular basic physical separation technique employing porous media that is permeable for liquids and particles smaller than the pore size of the filter, but serves as a trap for particles above this specific size. It is 
an effective tool for removing solid particles with low settling velocities from liquid suspensions. The choice of the filter media (more precisely, its pore size) defines the particle diameter cut-off value. However, there is a trade-off between increasing selectivity (lowering cut-off) and permeability: applications that aim to capture very small particle sizes require prolonged time or pressurization. During the process, a so-called "filter cake" builds up on the entry surface from the particulate matter that becomes retained. This gradually growing layer increases filtering efficiency with time, but also raises the flow resistance of the filter, necessitating regular cleanup actions (filter change or backwash) to restore its original performance. The frequency of cleaning is determined by the buildup rate (and thus, the particulate load) specific to the actual application.

In the case of road runoff, filtering often takes place spontaneously when contaminated water infiltrates to the ground (fully or partially) either during routing (flowing through unpaved ditches and swales) or while being stored in detention basins or ponds. Yet, in most cases the filter media is frequently not a result of deliberate choice but simply given by local soil conditions. It has been shown that soils usually perform well at retaining contamination [17, 23-25], but also inevitably become severely polluted themselves, without possibility of regeneration, ending up as hazardous waste $[23,26]$. The targeted application of filtering as a runoff contaminant removal technique is rare and its benefits are rather overlooked.

The goal of the experiment presented in this study was to quantify and characterize the performance of a cheap and widely available filter media, i.e. quartz sand, which provides good permeability and particle capture potential while allowing for future regeneration as well. Similarly to the sedimentation tests, real-world road runoff was used

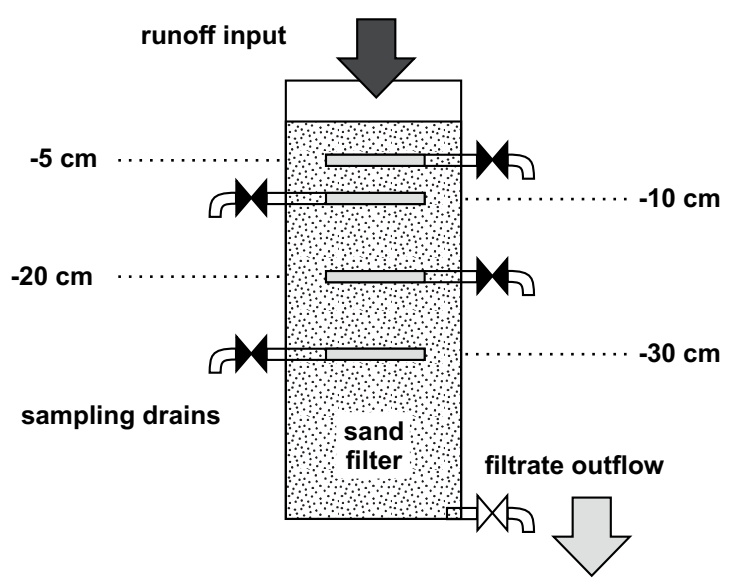

Fig. 2 Experimental setup used for the filtering tests in this test, too. The experimental setup (Fig. 2) consisted of a $50 \mathrm{~cm}$ tall transparent plastic column of $20 \mathrm{~cm}$ diameter, equipped with cross-sectional drain tubes at four different depths (the tubes were perforated only in the central area to eliminate the wall-effect). The column was filled up with commercial paving sand $(0.007 \mathrm{~mm}<\mathrm{D}<1 \mathrm{~mm})$ so that the drains were located 5, 10, 20 and $30 \mathrm{~cm}$ below the surface of the filter bed. The bottom of the device was also equipped with a drain tap to enable the control of the water table within the column (the actual level of the water table could be monitored by a piezometric tube).

Two independent tests were executed (each one using new filter material) with slightly different scenarios. In the first test, $1500 \mathrm{~mm}$ of raw runoff was dispensed without any pre-treatment on the column over a day (considering a 1:1 areal ratio between the donor impervious surface and the infiltration facility, this is equivalent of 3-5 years of runoff in Hungary, depending on inevitable variations in annual precipitation). Samples were taken from all four drains at three distinct time intervals (initial, midpoint and final stage), along with the raw input. In the second test, the same amount of runoff was introduced to the column after an hour-long initial settling period, and samples were taken only from the two upper drains, along with the input.

All samples were analyzed for TPH, chemical oxygen demand (COD), polycyclic aromatic hydrocarbons (PAH) and dissolved $\mathrm{Zn}$. Samples from the first test were also analyzed for dissolved $\mathrm{Cu}$, and some samples from both tests were analyzed for total $\mathrm{Zn}$ and $\mathrm{Cu}$ as well. Following the first test, three layers of the excavated filter bed (the top $2 \mathrm{~cm}$, the next $3 \mathrm{~cm}$ and the next $5 \mathrm{~cm}$ ) were sampled and analyzed for TPH, PAH, total $\mathrm{Zn}$ and $\mathrm{Cu}$, along with a blank sample from the unused filter material (representing background). The aim was to investigate the penetration and accumulation of these contaminants within the filter material.

\subsection{Analytical procedures}

All samples were analyzed in an accredited laboratory, where sample preparation procedures and measurements were done in accordance with the relevant Hungarian (MSZ) and international (ISO, EN, EPA) standards and methods, summarized in Table 1. TSS were quantified by gravimetric method, following a filtration step using 0.45 $\mu \mathrm{m}$ pore size filters. COD was measured by titration, using potassium dichromate. TPH (including both the volatile and the extractable fractions, $\mathrm{C} 5-\mathrm{C} 40$ ) were quantified by gas chromatography (GC). PAH (the 16 substances listed 
Table 1 Standards and methods applied for quantification of pollutants

\begin{tabular}{lcc}
\hline & liquid samples & solid samples \\
\hline TSS & MSZ 260-3:1973 & - \\
COD & MSZ ISO 6060:1991 & - \\
& & MSZ 21470-105:2004, MSZ \\
TPH & MSZ E 20361:2004 & 21470-92:1998 MSZ 21470- \\
& MSZ 20354:2003 & 94:2001 \\
PAH & MSZ 1484-6:2003 & MSZ 21470-84:2002 \\
& MSZ 1484-3:2006 & MSZ EN 13657:2003 \\
Zn, Cu & EPA Method 6020 & EPA Method 6020 \\
\hline
\end{tabular}

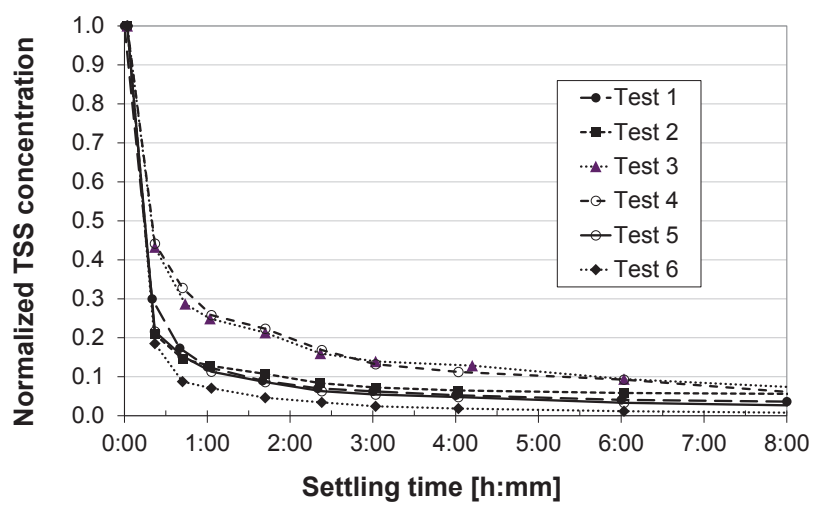

Fig. 3 Concentration profiles of total suspended solids (TSS) during the settling tests (values are normalized relative to the initial concentrations)

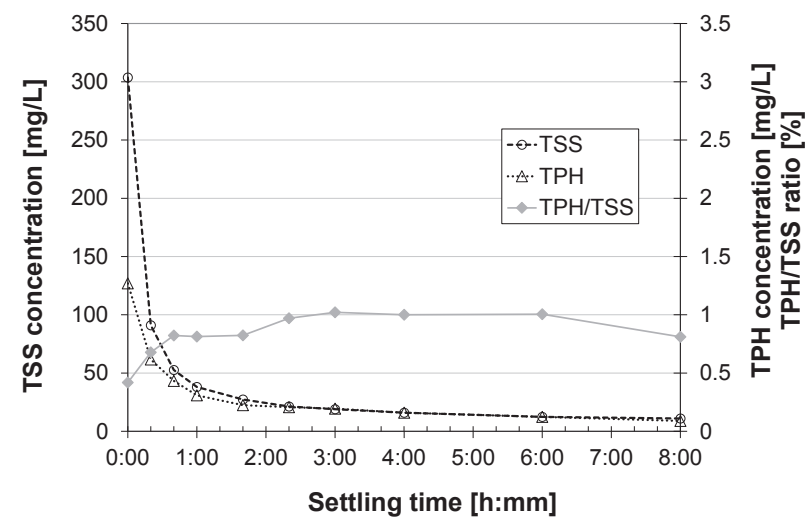

Fig. 4 Concentration profiles of total suspended solids (TSS) and total petroleum hydrocarbons (TPH) during the first settling test

by the US EPA and, in addition, 1-methyl-naphthalene, 2-methyl-naphthalene and benz(e)pyrene) were measured by gas chromatography - mass spectrometry (GC-MS). Zinc and copper were determined using inductively coupled plasma - mass spectrometry (ICP-MS). The accuracy of quantification was reported to be $\pm 25 \%$.

\section{Results and discussion}

Details of the results obtained from the experiments with the two runoff treatment techniques are presented and discussed in the subsequent sections.

\subsection{Sedimentation tests}

Although the initial suspended solid concentrations of the six tests ranged from roughly 300 to $1500 \mathrm{mg} / \mathrm{L}$, the settling curves exhibit identical pattern for all experiments, as presented in Fig. 3 (showing normalized values for easier comparison). Three stages can be distinguished on the graphs: there was a rapid drop in concentrations in the initial 40 minutes of the experiments, followed by a rather moderate decrease in the next 2 hours, after which further reductions were extremely slow, despite the prolonged time available. As a general rule of thumb, it can be stated that up to $75-90 \%$ of the suspended solids load (by mass) tends to settle out within 1 hour, if not disturbed by flow. Mild flows, which are present in well-designed settling basins, are not expected to significantly change this figure.

For one of the tests, TPH was measured along with TSS in order to investigate the relationship between particles and mineral oil derived hydrophobic pollutants. As Fig. 4 shows, TPH do have an apparent tendency to settle, which agrees with the findings of Buzás et al. [22], i.e. that TPH contamination emitted under ordinary traffic conditions (where the occurrence of major oil spills or leaks is negligible) tends to stick to the surface of small particles. Indeed, the principle difference between the settling curves of TSS and TPH indicates that TPH are less related to the fastest settling (i.e. the largest and heaviest) particles, but mimic the behavior of slowly settling ones. This kind of deviation may also be partly explained by the difference in the specific surface available for TPH adsorption in the case of larger and smaller particles (the former offer less adsorption possibility relative to their mass). The observed concentrations also suggest that roughly $1 \%$ of the mass of fine suspended particles in road runoff consists of TPH.

Despite its outstanding reduction capability regarding solids and particle-bound pollutants, sedimentation is not a sufficient treatment solution by itself. Designing settling objects with long residence times does not pay off and often conflicts with space restrictions as well. In addition, requirements for the treatment of dissolved pollutants are certainly not met by this technique, either. Sedimentation basins, however, do have their niche in a road runoff treatment system as relieving units that take substantial particulate load off the consecutive, more sensitive units. It must also be noted, that the available volume of a settling chamber gradually decreases over time due to the settled material, thus regular inspection and cleaning is essential to keep up the desired efficiency of these units. 


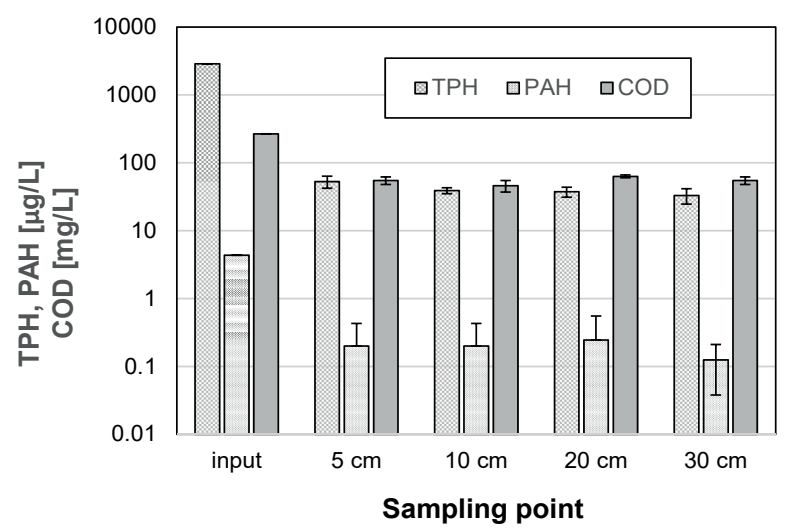

Fig. 5 Concentrations of TPH, PAH and COD in the feed and filtrate samples of filter test \#1 (bars indicate variance in time)

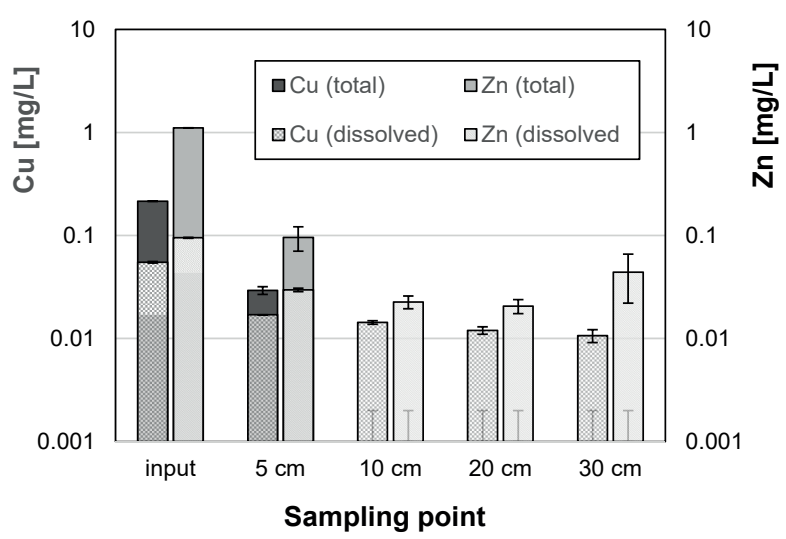

Fig. 6 Concentrations of $\mathrm{Cu}$ and $\mathrm{Zn}$ in the feed and filtrate samples filter test \#1 (bars show variance in time). Note that total concentrations were measured only in the feed and the first drain

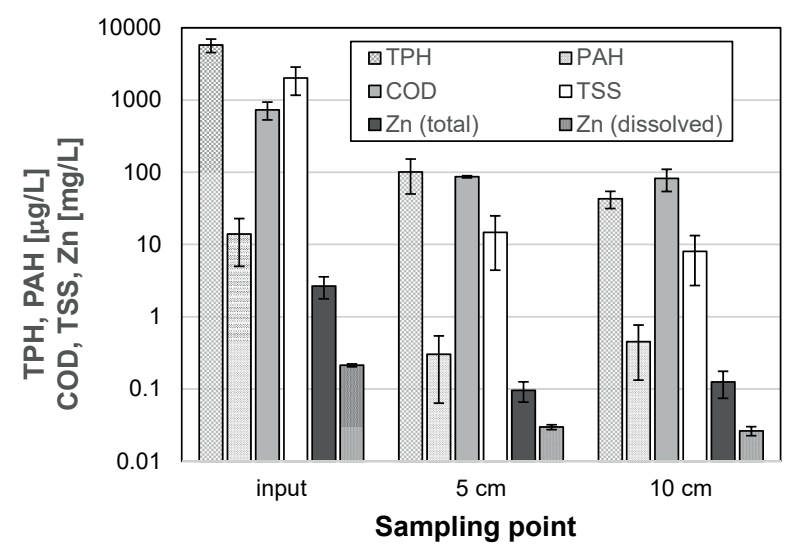

Fig. 7 Concentrations of TPH, PAH, COD, TSS and $\mathrm{Zn}$ in the feed and filtrate samples of filter test \#2 (bars indicate variance in time)

\subsection{Filtering tests}

Sand filtering proved to be remarkably efficient for removing all investigated compounds from road runoff. As shown by Fig 5, the concentration of TPH was reduced by approximately two orders of magnitude, while PAH and COD were lowered by roughly one order of magnitude. It was also clear that the removal took place in the topmost layer, as the change was already reflected by the samples taken from the first drain tap. No significant variation was observed between samples taken from the same drain taps at different times during the experiment, suggesting that filter performance is stable. Fig. 6 reveals similar results for $\mathrm{Cu}$ and $\mathrm{Zn}$, removing around one order of magnitude as far as total concentrations are concerned, while being less pronounced regarding the dissolved fraction. Since sand is not a specifically good adsorbent (lacking organic materials and clay minerals), this phenomenon met with prior anticipations.

The results gained from the first test were confirmed by the second one, as presented in Fig. 7. Concerning the working mechanism of filtration, the removal efficiency of this technique for particulates is not supposed to decrease over time, as filter cake will build up on the surface of the filter layer. This phenomenon could already be observed at the first test, where the runoff was introduced to the filter without any previous settling, causing the permeability to gradually deteriorate towards the end of the experiment. In the second test, the primary settling helped to maintain the original permeability of the filter column throughout the entire experiment, while the efficiency remained the same. Therefore, as a general rule of thumb, it is always advised to combine filtering with a primary sedimentation unit in order to provide longer lifetime for the filter matrix.

Despite the similar inputs, the removal rate of dissolved $\mathrm{Zn}$ was found to be much better for the second experiment (87\%) than for the first one (69\%), suggesting that the adsorption of dissolved heavy metals on sand particles is subject to variation. Differences in speciation might be a possible explanation for the observed change, however this was not studied in the present screening test. Nevertheless, it has been shown that certain reduction of dissolved metal fractions can be expected even from this relatively inert material (in terms of adsorption potential). Different other studies investigating the adsorption of heavy metal cations to quartz sand came to various conclusions [27-29], which underlines the need for further research in this field.

Analysis of the filter material layers after the first test confirmed the findings based on the filtrate concentrations. Pollutants were found to have been accumulated within the topmost layer of the filter column. As shown by Table 2, the penetration depths of the examined contaminants were fairly shallow: in the deeper strata only TPH were present in detectable (although severely reduced) amounts other than the background value. 
Table 2 Pollutant concentrations in the filter material after test \#1, in comparison with the unused filter material (background)

\begin{tabular}{lcccc}
\hline$[\mathrm{mg} / \mathrm{kg}]$ & $\mathrm{TPH}$ & $\mathrm{PAH}$ & $\mathrm{Cu}$ & $\mathrm{Zn}$ \\
\hline $0-2 \mathrm{~cm}$ & 447 & 0.474 & 17.4 & 134 \\
$2-5 \mathrm{~cm}$ & 6.3 & $\mathrm{ND}$ & 1.74 & 16.3 \\
$5-10 \mathrm{~cm}$ & 3.2 & $\mathrm{ND}$ & 1.49 & 13.1 \\
background & - & - & 1.57 & 16.9 \\
\hline
\end{tabular}

\section{Conclusions}

Sedimentation and sand filtration tests conducted using genuine road runoff proved that these simple and cheap, robust solutions are capable of fairly good contamination removal mainly, but not exclusively, for particle-bound pollutants. Sedimentation is a useful tool for separating the majority of suspended load mass, provided that the design of the facility ensures that horizontal flow is kept at low velocity in the settling basin. Maintenance of such objects is relatively hassle-free, consisting of periodic checks and occasional sludge removal. Sand filtration is effective in reducing the load of fine suspended particles (including the bulk share of heavy metals as well as TPH and PAH

\section{References}

[1] Opher, T., Friedler, E. "Factors affecting highway runoff quality", Urban Water Journal, 7(3), pp. 155-172, 2010. https://doi.org/10.1080/15730621003782339

[2] Göbel, P., Dierkes, C., Coldewey, W. G. "Storm water runoff concentration matrix for urban areas", Journal of Contaminant Hydrology, 91(1-2), pp. 26-42, 2007.

https://doi.org/10.1016/j.jconhyd.2006.08.008

[3] Budai, P., Clement, A. "A novel approach for road runoff sampling", Periodica Polytechnica Civil Engineering, 56(1), pp. 79-85, 2012. https://doi.org/10.3311/pp.ci.2012-1.09

[4] Shinya, M., Tsuchinaga, T., Kitano, M., Yamada, Y., Ishikawa, M. "Characterization of heavy metals and polycyclic aromatic hydrocarbons in urban highway runoff", Water Science and Technology, 42(7-8), pp. 201-208, 2000.

https://doi.org/10.2166/wst.2000.0570

[5] Huber, M., Welker, A., Helmreich, B. "Critical review of heavy metal pollution of traffic area runoff: Occurrence, influencing factors, and partitioning", Science of the Total Environment, 541, pp. 895-919, 2016.

https://doi.org/10.1016/j.scitotenv.2015.09.033

[6] Kayhanian, M., Fruchtman, B. D., Gulliver, J. S., Montanaro, C., Ranieri, E., Wuertz, S. "Review of highway runoff characteristics: Comparative analysis and universal implications", Water Research, 46(20), pp. 6609-6624, 2012.

https://doi.org/10.1016/j.watres.2012.07.026

[7] Petrucci, G., Gromaire, M.-C., Shorshani, M. F., Chebbo, G. "Nonpoint source pollution of urban stormwater runoff: a methodology for source analysis", Environmental Science and Pollution Research, 21(17), pp. 10225-10242, 2014. https://doi.org/10.1007/s11356-014-2845-4 adsorbed to the surface of particles) by at least one order of magnitude. Contaminant capture was observed to take place already in the upper few centimeters of the filter bed. Less prominent, but still fair reduction was experienced for the dissolved fraction of two heavy metals (although varying performance warns that efficiency figures should be treated with caution and be studied further). The service life of sand filter beds can be estimated to be several years or even decades without need for major maintenance activity, however this figure depends on their depth and the ratio between the size of the infiltration zone and the connected impervious area, i.e. the associated pollutant load (especially that of coarse particles). The latter can easily be minimized by utilizing sedimentation as pre-treatment stage.

The results presented in this study provide background information for road infrastructure designers and managers to plan and to operate low-cost, low maintenance runoff conveyance and treatment systems. The outcomes will also assist further studies that aim to investigate more complex runoff treatment systems, involving e.g. adsorption units, which target the capturing of dissolved pollutants.

[8] Thorpe, A., Harrison, R. M. "Sources and properties of non-exhaust particulate matter from road traffic: A review", Science of the Total Environment, 400(1-3), pp. 270-282, 2008.

https://doi.org/10.1016/j.scitotenv.2008.06.007

[9] Pulles, T., van der Gon, H. D., Appelman, W., Verheul, M. "Emission factors for heavy metals from diesel and petrol used in European vehicles", Atmospheric Environment, 61, pp. 641-651, 2012. https://doi.org/10.1016/j.atmosenv.2012.07.022

[10] Lawrence, S., Sokhi, R., Ravindra, K., Maoa, H., Prain, H. D., Bull, I. D. "Source apportionment of traffic emissions of particulate matter using tunnel measurements", Atmospheric Environment, 77, pp. 548-557, 2013.

https://doi.org/10.1016/j.atmosenv.2013.03.040

[11] Gunawardena, J., Egodawatta, P., Ayoko, G. A., Goonetilleke, A. "Atmospheric deposition as a source of heavy metals in urban stormwater", Atmospheric Environment, 68, pp. 235-242, 2013. https://doi.org/10.1016/j.atmosenv.2012.11.062

[12] Vaze, J., Chiew, F.H.S. "Experimental study of pollutant accumulation on an urban road surface", Urban Water, 4(4), pp. 379-389, 2002. https://doi.org/10.1016/S1462-0758(02)00027-4

[13] Gbeddy, G., Jayarathne, A., Goonetilleke, A., Ayoko, G. A., Egodawatta, P. "Variability and uncertainty of particle build-up on urban road surfaces", Science of the Total Environment, 640-641, pp. 1432-1437, 2018. https://doi.org/10.1016/j.scitotenv.2018.05.384

[14] Zafra, C., Tempranob, J., Suárez, J. "A simplified method for determining potential heavy metal loads washed-off by stormwater runoff from road-deposited sediments", Science of The Total Environment, 601-602, pp. 260-270, 2017. https://doi.org/10.1016/j.scitotenv.2017.05.178 
[15] Budai, P., Clement, A. "Refinement of national-scale heavy metal load estimations in road runoff based on field measurements", Transportation Research Part D: Transport and Environment, 16(3), pp. 244-250, 2011.

https://doi.org/10.1016/j.trd.2010.12.003

[16] Barbosa, A. E., Fernandes, J. N. "Assessment of treatment systems for highway runoff pollution control in Portugal", Water Science and Technology, 59(9), pp. 1733-1742, 2009.

https://doi.org/10.2166/wst.2009.181

[17] Mikkelsen, P. S., Häfliger, M., Ochs, M., Jacobsen, P., Tjell, J.C., Boller, M. "Pollution of soil and groundwater from infiltration of highly contaminated stormwater - a case study", Water Science and Technology, 36(8-9), pp. 325-330, 1997. https://doi.org/10.1016/S0273-1223(97)00578-7

[18] Hares, R. J., Ward, N. I. "Comparison of the heavy metal content of motorway stormwater following discharge into wet biofiltration and dry detention ponds along the London Orbital (M25) motorway", Science of The Total Environment, 235(1-3), pp. 169-178, 1999. https://doi.org/10.1016/S0048-9697(99)00210-7

[19] Barbosa, A. E., Hvitved-Jacobsen, T. "Highway runoff and potential for removal of heavy metals in an infiltration pond in Portugal", Science of The Total Environment, 235(1-3), pp. 151-159, 1999. https://doi.org/10.1016/S0048-9697(99)00208-9

[20] Revitt, D. M., Shutes, R. B. E., Jones, R. H., Forshaw, M., Winter, B. "The performances of vegetative treatment systems for highway runoff during dry and wet conditions", Science of The Total Environment, (334-335), pp. 261-270, 2004. https://doi.org/10.1016/j.scitotenv.2004.04.046

[21] Gill, L. W., Ring, P., Higgins, N. M. P., Johnston, P. M. "Accumulation of heavy metals in a constructed wetland treating road runoff", Ecological Engineering, 70, pp. 133-139, 2014. https://doi.org/10.1016/j.ecoleng.2014.03.056

[22] Buzás, K., Budai, P., Clement, A. "Contamination and treatment of highway runoff", Pollack Periodica, 3(3), pp. 79-89, 2008. https://doi.org/10.1556/Pollack.3.2008.3.7
[23] Dierkes, C., Geiger, W. F. "Pollution retention capabilities of roadside soils", Water Science and Technology, 39(2), pp. 201-208, 1999. https://doi.org/10.1016/S0273-1223(99)00024-4

[24] Murakami, M., Sato, N., Anegawa, A., Nakada, N., Harada, A. et al. "Multiple evaluations of the removal of pollutants in road runoff by soil infiltration", Water Research, 42(10-11), 2745-2755, 2008. https://doi.org/10.1016/j.watres.2008.02.004

[25] Horváth, A., Kalicz, P., Farsang, A., Balázs, P., Berki, I., Bidló, A. "Influence of human impacts on trace metal accumulation in soils of two Hungarian cities", Science of The Total Environment, 637-638, pp. 1197-1208, 2018. https://doi.org/10.1016/j.scitotenv.2018.05.033

[26] Schipper, P. N. M., Comans, R. N. J., Dijkstra, J. J., Vergouwen, L. "Runoff and windblown vehicle spray from road surfaces, risks and measures for soil and water", Water Science and Technology, 55(3), 87-96, 2007. https://doi.org/10.2166/wst.2007.076

[27] Awan, M. A, Qazi, I. A., Khalid, I. "Removal of heavy metals through adsorption using sand", Journal of Environmental Sciences, 15(3), pp. 413-416, 2003. [online] Available at: https://www. researchgate.net/publication/10597643_Removal_of_heavy_metals_through_adsorption_using_sand [Accessed: 11.04.2019]

[28] Pappalardo, L., Jumean, F., Abdo, N. "Removal of Cadmium, Copper, Lead and Nickel from Aqueous Solution by White, Yellow and Red United Arab Emirates Sand", American Journal of Environmental Sciences, 6(1), pp. 41-44, 2010. [online] Available at: https://www.researchgate.net/publication/49590036_Removal_ of_Cadmium_Copper_Lead_and_Nickel_from_Aqueous_Solution by_White_Yellow_and_Red_United_Arab_Emirates_Sand [Accessed: 11.04.2019]

[29] Haile, T. M., Fuerhacker, M. "Simultaneous Adsorption of Heavy Metals from Roadway Stormwater Runoff Using Different Filter Media in Column Studies", Water, 10(9), 2018. https://doi.org/10.3390/w10091160 